\title{
Erratum to: The aldosterone to renin ratio in the evaluation of patients with incidentally detected adrenal masses
}

M. Tzanela - G. Effraimidis - D. Vassiliadi •

A. Szabo • N. Gavalas • A. Valatsou •

E. Botoula $\cdot$ N. C. Thalassinos

Published online: 9 December 2012

(C) Springer Science+Business Media New York 2012

Erratum to: Endocrine (2007) 32:136-142

DOI 10.1007/s12020-007-9028-8

In the original publication, the surname of the second author is misspelled. The correct surname is Effraimidis.

The online version of the original article can be found under doi: 10.1007/s12020-007-9028-8.

M. Tzanela ( $\square)$ · G. Effraimidis · D. Vassiliadi · A. Szabo ·

N. Gavalas · A. Valatsou - E. Botoula · N. C. Thalassinos

Department of Endocrinology and Diabetes Center,

Evangelismos Hospital, 45-47, Ipsilantous St., 106-76 Athens,

Greece

e-mail: mtzanel@med.uoa.gr 